\title{
Assessment of human exposure to benzene through foods from the Belgian market
}

\author{
Raquel Medeiros Vinci ${ }^{\text {a,b }}$, Liesbeth Jacxsens ${ }^{\text {a,b }}$, Joris Van Loco ${ }^{c}$, Eric Matsiko ${ }^{\text {a }}$, Carl Lachat ${ }^{\text {a,b,d }}$, \\ Thibault de Schaetzen ${ }^{c}$, Michael Canfyn ${ }^{c}$, Ilse Van Overmeire ${ }^{c}$, Patrick Kolsteren ${ }^{\text {a,b,d }}$, \\ Bruno De Meulenaer ${ }^{\mathrm{a}, \mathrm{b}, *}$ \\ ${ }^{a}$ Department of Food Safety and Food Quality, Faculty of Bioscience Engineering, Ghent University, Coupure Links 653, B-9000 Ghent, Belgium \\ ${ }^{\mathrm{b}}$ Food2Know, Coupure Links 653, B-9000 Ghent, Belgium \\ ${ }^{\mathrm{c}}$ Food, Medicines and Consumer Safety, Scientific Institute of Public Health, Rue Juliette Wytsmanstraat 14, 1050 Brussels, Belgium \\ ${ }^{\mathrm{d}}$ Nutrition and Child Health Unit, Institute of Tropical Medicine, Antwerp, Belgium
}

\section{A R T I C L E I N F O}

\section{Article history:}

Received 11 August 2011

Received in revised form 12 February 2012

Accepted 9 March 2012

Available online 5 April 2012

\section{Keywords:}

Benzene

Food

Exposure assessment

Probabilistic analysis

Monte Carlo simulation

\begin{abstract}
A B S T R A C T
Benzene is a volatile organic compound known to be carcinogenic to humans (Group 1) and may be present in food. In the present study, 455 food samples from the Belgian market were analyzed for benzene contents and some possible sources of its occurrence in the foodstuffs were evaluated. Benzene was found above the level of detection in $58 \%$ of analyzed samples with the highest contents found in processed foods such as smoked and canned fish, and foods which contained these as ingredients (up to $76.21 \mu \mathrm{g} \mathrm{kg}^{-1}$ ). Unprocessed foods such as raw meat, fish, and eggs contained much lower concentrations of benzene. Using the benzene concentrations in food, a quantitative dietary exposure assessment of benzene intake was conducted on a national representative sample of the Belgian population over 15 years of age. The mean benzene intake for all foods was $0.020 \mu \mathrm{g} \mathrm{kg} \mathrm{bw} \mathrm{d}{ }^{-1}$ according to a probabilistic analysis. These values are below the minimum risk level for oral chronic exposure to benzene $\left(0.5 \mu \mathrm{g} \mathrm{kg} \mathrm{bw} \mathrm{d}^{-1}\right)$. (c) 2012 Elsevier Ltd. All rights reserved.
\end{abstract}

\section{Introduction}

Benzene is a volatile organic compound (VOC) known to be carcinogenic to humans and is classified as a Group 1 carcinogen (IARC, 1987). Benzene is commonly used in the production process of other chemicals, detergents, paints, and plastics and may be found in the environment due to gasoline vapors, burning of fossil fuels, vehicle emissions, wood burning and cigarette smoke. In addition, the occurrence of benzene in food and beverages has also been reported (Mcneal et al., 1993; Heikes et al., 1995; FlemingJones and Smith, 2003; Lachenmeier et al., 2008; Nyman et al., 2008; Van Poucke et al., 2008). Several factors either related to food processing conditions or to bad manufacturing practices are potential sources of benzene in foodstuffs (Becalski and Nyman, 2009). Food processing conditions such as irradiation treatments and high temperatures processes (e.g. roasting) have been linked to benzene formation. Under such conditions, the decomposition of certain amino acids present in food (e.g. phenylalanine) (Kjallstrand and Petersson, 2001; Ahn, 2002; Zhu et al., 2004; Sommers et al., 2006) and the decarboxylation of benzoate (widely

\footnotetext{
* Corresponding author at: Department of Food Safety and Food Quality, Faculty of Bioscience Engineering, Ghent University, Coupure Links 653, B-9000 Ghent, Belgium. Tel.: +329 26461 66; fax: +32926462 15 .

E-mail address: Bruno.DeMeulenaer@UGent.be (B. De Meulenaer).
}

used food preservative) (Matthews and Sangster, 1965) may take place and yield benzene formation. Further research regarding benzene formation from the oxidative decarboxylation of benzoate in the absence of irradiation treatments, has been described in literature, regarding the presence of hydroxyl radicals in food (Gardner and Lawrence, 1993; Mcneal et al., 1993; Lachenmeier et al., 2008). Accordingly, hydroxyl radical formation is promoted by the presence of ascorbic acid and transition metal ions (e.g. $\mathrm{Cu}^{2+}$ or $\mathrm{Fe}^{3+}$ ions). Other variables such as temperature and $\mathrm{pH}$ will also influence benzene formation from benzoate. Noteworthy is the fact that both, benzoates and ascorbic acid may be naturally present in foodstuffs or added as food additives.

Benzene can also be introduced in food through migration from various packaging materials, or from contamination of the environment and water supply (Jickells et al., 1990; Varner et al., 1991; Bolzoni et al., 1996; Knox and Canter, 1996). Contaminated carbon dioxide was also reported as a benzene source in beer and in water (Long, 1999; Wu et al., 2006). The use of hexane in solvent extraction of vegetable oils may also contribute to benzene occurrence in food (Masohan et al., 2000). Finally, flavors incorporated into foodstuffs through smoking (with wood or charcoal) or addition of liquid smoke are another source of benzene in foods (Wittkowski et al., 1990; Mcneal et al., 1993).

Currently there are no legal limits worldwide for benzene in food products or beverages, thus the limit in drinking water is mostly used as a reference value. This reference is limited to 
$10 \mu \mathrm{g} \mathrm{L}^{-1}$ by the World Health Organization (WHO, 1996), $5 \mu \mathrm{g} \mathrm{L}^{-1}$ by the US Environmental Protection Agency (US EPA, 1985) and $1 \mu \mathrm{g} \mathrm{L}^{-1}$ by the European Council (EC, 1998). A minimum risk level (MRL) of $0.5 \mu \mathrm{g} \mathrm{kg} \mathrm{bw} \mathrm{d}^{-1}$ has been established for oral chronic exposure by the US Public Health Service Agency for Toxic Substances and Disease Registry (ATSDR, 2007).

With respect to risk characterization, MOE (Margin Of Exposure) values ranging from 400000-2000000 have been recently established for benzene dietary exposure based on a $\mathrm{BMDL}_{10}$ of $17.6 \mathrm{mg} \mathrm{kg} \mathrm{bw} \mathrm{d}^{-1}$ derived from female rat Zymbal gland carcinoma (Smith et al., 2010; Benford et al., 2010). MOE values represent the ratio between a particular point on the dose-response curve leading to tumors in experimental animals and the human intake. Although MOE values higher than 10000 are considered to be of low concern from a public health point of view (EFSA, 2005), Smith et al. (2010) and Benford et al. (2010) highlight several uncertainties related to the calculation of the MOE values. These include the difficulty in obtaining relevant exposure data, limited toxicity data for oral exposure, the relevance of animal data for human and the importance of consistency and robustness of animal tumor data across species.

The objective of this study was to determine the occurrence of benzene in foods of the Belgian market and identify potential sources of this contaminant in foodstuffs. Furthermore a quantitative exposure assessment of dietary benzene intake was performed for the Belgian population over 15 years of age and compared to the MRL established for oral chronic exposure.

\section{Experimental}

\subsection{Supplies and reagents}

Benzene (99.9\%) and benzene- $d_{6}$ with isotopic purity of $99.9 \%$ (Supelco) were both supplied by Sigma-Aldrich (Bornem, Belgium) and stored at $4{ }^{\circ} \mathrm{C}$. Sodium hydroxide was obtained from BDH (Poole, England) and boric acid was supplied by Merck (Darmstadt, Germany). Antifoam silicone 411 Rhodorsil $^{\circledR}$ was purchased from VWR (Leuven, Belgium). Deionised water (Milli-Q Millipore Corp.) of $18.0 \mathrm{M} \Omega \mathrm{cm}^{-1}$ resistivity was used throughout.

\subsection{Sampling plan for benzene analysis in food}

The sampling plan included four groups based on potential sources for benzene occurrence. Group 1 - foods with added benzoate, based on the regulation Directive 95/2/EC (EC, 1995) and a label survey performed in this study (E210-E213). These foodstuffs include, non-alcoholic drinks, alcoholic drinks $(<15 \%$ alcohol), sauces ( $<60 \%$ fat), spreadable salads, olives, semi-preserved fish and fish products, dips and tapenades, chilled meals and salads. Group 2 - foods which may naturally contain benzoic acid, based on Vandevijvere et al. (2009). This group includes smoothies and fruit juices, dairy drinks and deserts enriched with fruit, fresh fruit, honey and fermented dairy products. Group 3 - foods which may contain benzene due to environmental/process contamination which include milk and dairy products, eggs, vegetables, non-refined oils, meat (raw, processed and patés) and fish (raw and processed). Group 4 - other foods, which include carbonated drinks, canned products (vegetables, meat, fish and ready to eat meals), frozen products (containing vegetables, meat and fish), breakfast cereals, cereal products, coffee and tea, chocolate, cakes and cookies, dairy desserts (different from the ones analyzed in Group 2), refined oils and margarines and foods where the addition of benzoate is allowed but did not contain according to the label.

A minimum of 10 samples were considered per food type mentioned in the four groups and a total of 455 food samples were analyzed for benzene contents. Food products were purchased from four different supermarket chains with good market share in Belgium and belonging to different brands which included $\mathrm{A}$, white and private labels.

\subsection{Determination of benzene contents in foodstuffs}

Foodstuffs were purchased and analyzed from March to October 2010. Samples were stored under the same conditions as those found in retail and analyzed prior to expiration date. Precautionary measures were taken to avoid sample contamination in the lab, such as storage and sample preparation in a segregated area from lab used for standards preparation and sample analysis. Solid and/ or fat containing samples were homogenized, followed by the addition of antifoam agent, borate buffer $(0.8 \mathrm{M}, \mathrm{pH} 10)$ and internal standard benzene- $d_{6}$ spike (concentration in the sample $\left.1 \mu \mathrm{g} \mathrm{kg}^{-1}\right)$. The use of borate buffer prevented artefactual benzene formation in foodstuffs possibly containing benzoate. Samples were distilled and $5 \mathrm{~mL}$ of distillate transferred to a headspace vial. Liquid non-containing fat samples were gently homogenized by shaking for $30 \mathrm{~s}$ and carbonaceous drinks were further degassed by sonicating $15 \mathrm{~mL}$ of the soft drink for $1.5 \mathrm{~min}$ until all carbon dioxide bubbles had disappeared. Of each of these samples, $4 \mathrm{~mL}$ was transferred to a headspace vial, and $1 \mathrm{~mL}$ of borate buffer $(0.8 \mathrm{M})$ and the internal standard benzene- $d_{6}\left(1.0 \mu \mathrm{g} \mathrm{kg}^{-1}\right)$ were added. All samples were analyzed by headspace-gas chromatography/mass spectrometry (HS-GC/MS). Chromatographic conditions and method are described in Medeiros Vinci et al. (2010). For quality control purposes each batch of distillations analysis (performed on the same day) was accompanied by a water blank sample, and a food blank sample (chocolate ice-cream) spiked with benzene and benzene- $d_{6}\left(1 \mu \mathrm{g} \mathrm{kg}^{-1}\right)$. For quantification, calibration water samples were spiked with benzene $\left(0,0.5,1,5,10\right.$ and $\left.20 \mu \mathrm{g} \mathrm{kg}^{-1}\right)$ and benzene- $d_{6}\left(1 \mu \mathrm{g} \mathrm{kg}^{-1}\right)$ and analyzed at the beginning and the end of each batch of samples. Identification and quantification criteria for benzene were based on the relative retention time of the quantification ion ( $\mathrm{m} / \mathrm{z} 78$ in SIM mode) and identification ions ( $\mathrm{m} / \mathrm{z} 77$ and 51 in SIM mode), being within the $0.5 \%$ margin of the relative retention time as determined in the standard sample. Ion ratios of $\mathrm{m} / \mathrm{z} 77$ divided by $\mathrm{m} / \mathrm{z} 78$ and $\mathrm{m} / \mathrm{z} 51$ divided by $\mathrm{m} / \mathrm{z}$ 78 were used to confirm benzene identity. LOD and LOQ for benzene extracted by distillation and HS-GC/MS were $\leqslant 0.5$ and $\leqslant 0.75 \mu \mathrm{g} \mathrm{kg}^{-1}$, respectively. For liquid non-fatty samples directly analyzed by HS-GC/MS, the LOD and LOQ were $\leqslant 0.14$ and $\leqslant 0.3 \mu \mathrm{g} \mathrm{kg}^{-1}$, respectively.

\subsection{Consumption data}

Food consumption data were obtained from the Belgian National Food Consumption Survey (BNFCS) of 2004. This survey is a national representative sample of food consumption of 3083 participants residing in Belgium of 15 years or older. Aims, design and methods of the BNFCS are described by De Vriese et al. (2005). Information on dietary intake was collected based on two non-consecutive 24 h recalls in combination with a self-administered food-frequency questionnaire. This approach allows information on intra-individual variation and therefore suitable for determining distributions of usual dietary intakes. Consumption data of foodstuffs analyzed for benzene contents (described in Section 2.2), were extracted from the BNFCS based on food name and facet strings which further refined the food product search. In general, all analyzed foodstuffs were reported in the BNFCS with an exception of ready to eat meals (e.g. chilled meals). These were not reported as commercial products but as homemade. Consumption data for this food category were obtained by calculating the sum of consumption of the relative percentage of all ingredients listed on the food product label. 
The usual food intake was determined from the total data set including also the 'zero intakes' (when a certain food type is not consumed by an interviewed individual) with the Multiple Source Method program (German Institute of Human Nutrition PostdamRehbrücke (DIfE), 2010). This method is characterized by a two-part shrinkage technique applied to residuals of two regression models (one for the positive daily intake and one for the event of consumption) and therefore accounting for the intra-individual variability.

Food intake was expressed as $\mathrm{kg} \mathrm{bw} \mathrm{d}^{-1}$ using self-reported body weight data.

\subsection{Exposure assessment}

Benzene dietary exposure included the analysis of three different scenarios (lower, medium and upper bound) related to data treatment of benzene non-detects (<LOD). Accordingly, non-detects data was considered zero, $1 / 2$ LOD and LOD for the lower, medium and upper bounds, respectively. For exposure assessment, foods were grouped in fourteen categories: non-alcoholic drinks, alcoholic drinks, sauces, dairy products, fruits and vegetables, meat and meat products, fish and fish products, cereal products, cookies and cakes, fats and oils, ready to eat meals, sugar and confectionary, miscellaneous and eggs.

\subsection{Probabilistic analysis}

Best fit distributions were applied to the lower bound scenario of benzene contents in the different food categories and to the consumption data. The type of distribution selected as best fitted for the lower bound was applied upon the other two scenarios of benzene concentrations (medium and upper bound). First order Monte Carlo simulations were performed considering 50000 iterations. Estimated benzene intake (mean, standard deviation and percentiles) was determined per food category separately and total benzene intake was calculated by considering all data for the food categories. Therefore the sum of the means of the subcategories intake is not necessarily equal to the mean intake of the overall category. Calculations were performed using the software package @Risk $^{\circledR}$ for Microsoft Excel version 5.5 (Palisade Corporation, US).

\section{Results and discussion}

\subsection{Occurrence of benzene in foods from the Belgian market}

A risk based sampling plan was elaborated based on the possible sources of benzene in foods, and therefore considered four groups: (1) foods with added benzoate; (2) foods which may naturally contain benzoic acid; (3) foods possibly related to benzene through environment/process contamination and (4) other foods. A total of 455 samples from the Belgian market were analyzed and benzene was detected above the LOD in 58\% of analyzed samples. Table 1 shows the percentage of benzene occurrence at different benzene levels in the four food groups. Groups 1 (foods with added benzoate), 4 (other foods) and 3 (possible environmental/ process contamination) were the groups with highest number of samples contaminated with benzene, $68 \%, 50 \%$ and $55 \%$, respectively. While in Group 2 (foods which may naturally contain benzoic acid), only $19 \%$ of the samples were positive for benzene. Of the total analyzed samples, $31 \%$ of them contained benzene levels above the EU limit for benzene in drinking water $\left(1 \mu \mathrm{g} \mathrm{kg}^{-1}\right)$ (EC, 1998 ) and $6 \%$ were above $10 \mu \mathrm{g} \mathrm{kg}^{-1}$, the WHO-limit for drinking water (WHO, 1996). Benzene occurrence was also reported in a wide range of foodstuffs by the United Sates Food and Drug Administration (FDA) during a five year study (Fleming-Jones and Smith, 2003). In fact, all analyzed foods contained benzene with an exception of American cheese and vanilla ice-cream. Higher benzene concentrations (1-190 $\mu \mathrm{g} \mathrm{kg}^{-1}$ ) were reported by Fleming-Jones and Smith (2003) relatively to the present study, however the FDA alerted to the fact that artefactual benzene could have been formed during analysis.

Although benzene formation from benzoate is described in literature (Gardner and Lawrence, 1993; Mcneal et al., 1993), benzene concentrations found in the four different food groups indicate that this is not the most probable cause for the levels found in the analyzed samples. Moreover, Group 1 includes some processed and fat containing foods, and therefore the possibility of environmental/process or other contamination routes in this group cannot be excluded. Consequently, food groups were reorganized into fourteen categories according to the food categorization adopted by the BNFCS database (De Vriese et al., 2005), and are presented in Table 2 together with the benzene contents determined in the foodstuffs.

Benzene was present in all food categories with exception of fresh eggs. Other categories such as alcoholic drinks and fruits and vegetables presented $<10 \%$ of benzene occurrence. Eight food categories (sauces, meat and meat products, fish and fish products, cereal products, cakes and cookies, fats and oils, ready to eat meals and miscellaneous) out of the fourteen categories contained benzene $(\geqslant$ LOD) with a percentage of occurrence ranging from $66 \%$ to $96 \%$. The highest benzene concentrations were observed in fish and fish products and correspond to smoked and canned fish products. Benzene contents ranged from 1.83 to $76.21 \mu \mathrm{g} \mathrm{kg}^{-1}$ for the smoked fish and up to $20.81 \mu \mathrm{g} \mathrm{kg}^{-1}$ for the canned fish products. On the other hand, the mean concentrations of benzene found in raw fish were $0.52 \pm 0.85 \mu \mathrm{g} \mathrm{kg}^{-1}$ and $3.15 \pm 4.21 \mu \mathrm{g} \mathrm{kg}^{-1}$ for non-fatty and fatty fish, respectively. This indicates that the smoking process and thermal treatment in enclosed systems (cans) are the main contributors for the presence of benzene in this food category and overall responsible for some of the highest concentrations found in the benzene data of this study.

Benzene concentrations up to $25.46 \mu \mathrm{g} \mathrm{kg}^{-1}$ were found in the food category of ready to eat meals. The highest benzene values were found in spreadable salads with $92 \%$ of benzene occurrence in this food subcategory. Benzoate is generally used as food additive in these foods, and was present in $89 \%$ of samples analyzed from this food category (according to label description). However, there are indications that in such complex foods, benzene is not predominantly originating from benzoate. Factors such as fat content, and presence of antioxidants might hinder the formation of benzene from benzoate (Medeiros Vinci et al., 2011). High benzene values correspond to spreadable salads containing smoked salmon

Table 1

Percentages of benzene occurrence at different concentration levels in foodstuffs from the Belgian market.

\begin{tabular}{|c|c|c|c|c|c|}
\hline \multirow[t]{2}{*}{ Food group } & \multirow[t]{2}{*}{$N$} & \multicolumn{4}{|c|}{ Benzene occurrence (\%) at different concentration levels $\left(\mu \mathrm{g} \mathrm{kg}^{-1}\right)$} \\
\hline & & $\leqslant$ LOD & $0.5-1.0$ & $1.0-10.0$ & $>10$ \\
\hline 1 & 148 & 32 & 28 & 35 & 5 \\
\hline 2 & 59 & 81 & 19 & 0 & 0 \\
\hline 3 & 82 & 50 & 7 & 39 & 4 \\
\hline 4 & 166 & 45 & 9 & 35 & 11 \\
\hline
\end{tabular}


Table 2

Benzene contents (mean, standard deviation and maximum, $\mu \mathrm{g} \mathrm{kg}^{-1}$ ) in the different food categories and subcategories analyzed.

\begin{tabular}{|c|c|c|c|c|c|c|}
\hline \multirow[t]{2}{*}{ Food category } & \multirow[t]{2}{*}{ Food subcategory } & \multicolumn{2}{|l|}{$N$} & \multicolumn{3}{|c|}{ Benzene $\left(\mu \mathrm{g} \mathrm{kg}^{-1}\right)$} \\
\hline & & Analyzed & $\geqslant$ LOD & Mean & Std & Maximum \\
\hline \multirow[t]{4}{*}{ Non-alcoholic drinks } & Beverages $^{a}$ & 28 & 14 & 1.30 & 2.72 & 11.52 \\
\hline & Smoothies and juices & 9 & 1 & 0.05 & 0.16 & 0.48 \\
\hline & Coffee, tea and infusions ${ }^{\mathrm{b}}$ & 12 & 2 & 0.21 & 0.47 & 1.33 \\
\hline & Water (carbonated) & 3 & 0 & 0.00 & 0.00 & 0.00 \\
\hline \multirow[t]{2}{*}{ Alcoholic drinks } & Spirits with $<15 \%$ alcohol & 4 & 1 & 0.25 & 0.50 & 1.00 \\
\hline & Beer & 6 & 0 & 0.00 & 0.00 & 0.00 \\
\hline Sauces & Sauces & 14 & 11 & 1.18 & 1.71 & 6.35 \\
\hline \multirow{3}{*}{ Dairy product } & Yogurts and desserts & 14 & 1 & 0.06 & 0.21 & 0.80 \\
\hline & Cheese & 13 & 10 & 0.47 & 0.31 & 0.86 \\
\hline & Milk and cream & 10 & 2 & 0.15 & 0.40 & 1.27 \\
\hline \multirow[t]{4}{*}{ Fruits and vegetables } & Olives & 2 & 2 & 1.85 & 0.40 & 2.13 \\
\hline & Fresh fruit & 10 & 0 & 0.00 & 0.00 & 0.00 \\
\hline & Fresh vegetables & 10 & 0 & 0.00 & 0.00 & 0.00 \\
\hline & Canned fuits and vegetables & 11 & 0 & 0.00 & 0.00 & 0.00 \\
\hline \multirow[t]{5}{*}{ Meat and meat products } & Processed (dried/cured/fermented) & 7 & 6 & 1.77 & 2.44 & 6.95 \\
\hline & Raw & 4 & 1 & 0.31 & 0.62 & 1.25 \\
\hline & Smoked & 5 & 3 & 3.52 & 2.63 & 6.06 \\
\hline & Patés & 6 & 6 & 1.06 & 0.80 & 1.92 \\
\hline & Canned & 7 & 3 & 0.97 & 1.22 & 2.57 \\
\hline \multirow[t]{5}{*}{ Fish and fish products } & Semi-preserved & 10 & 4 & 1.68 & 3.74 & 11.97 \\
\hline & Raw (fatty) & 4 & 4 & 3.15 & 4.21 & 9.44 \\
\hline & Raw (non-fatty) & 6 & 2 & 0.52 & 0.85 & 2.00 \\
\hline & Smoked & 10 & 10 & 18.90 & 26.14 & 76.21 \\
\hline & Canned & 16 & 15 & 7.40 & 6.02 & 20.81 \\
\hline \multirow[t]{2}{*}{ Cereal products } & Pasta, rice, bread & 7 & 3 & 0.59 & 0.89 & 2.25 \\
\hline & Breakfast cereals & 18 & 18 & 3.15 & 1.82 & 7.15 \\
\hline Cakes and cookies & Cookies and cakes & 6 & 5 & 0.81 & 0.51 & 1.51 \\
\hline \multirow[t]{3}{*}{ Fats and oils } & Butter & 5 & 5 & 0.59 & 0.14 & 0.68 \\
\hline & Non-Refined oils & 12 & 11 & 2.19 & 1.45 & 5.04 \\
\hline & Refined oils & 11 & 11 & 0.74 & 0.65 & 2.55 \\
\hline \multirow[t]{4}{*}{ Ready to eat meals } & Spreadable salads & 68 & 62 & 2.79 & 5.60 & 25.46 \\
\hline & Dips and tapenades & 17 & 15 & 1.44 & 1.46 & 6.48 \\
\hline & Chilled meals & 14 & 11 & 1.11 & 1.02 & 3.68 \\
\hline & Canned ready to eat foods & 12 & 3 & 0.42 & 0.94 & 3.13 \\
\hline \multirow[t]{5}{*}{ Sugar and confectionaries } & Honey & 9 & 0 & 0.00 & 0.00 & 0.00 \\
\hline & Chocolate & 14 & 13 & 1.54 & 0.84 & 2.82 \\
\hline & Ice creams & 8 & 2 & 0.25 & 0.47 & 1.17 \\
\hline & Candy & 9 & 1 & 0.25 & 0.24 & 0.73 \\
\hline & Jams & 5 & 0 & 0.00 & 0.00 & 0.00 \\
\hline Miscellaneous & Fried frozen products & 10 & 7 & 0.85 & 0.89 & 2.52 \\
\hline Eggs & Fresh eggs (commercial and private) & 9 & 0 & 0.00 & 0.00 & 0.00 \\
\hline
\end{tabular}

a Benzene analysis performed in products ready for consumption (e.g. concentrated juices diluted according to label instructions).

b Analysis performed after brewering preparation, according to packaging instructions.

(up to $19.69 \mu \mathrm{g} \mathrm{kg}^{-1}$ ) or tuna (up to $25.46 \mu \mathrm{g} \mathrm{kg}^{-1}$ ) as main ingredients. Although an environmental contamination might not be excluded, the process contamination is the most likely contamination route here.

Another example that could indicate that food processing is a possible route of benzene contamination is found in the category of meat and meat products. The highest benzene levels (up to $6.95 \mu \mathrm{g} \mathrm{kg}^{-1}$ ) were observed in smoked and preserved meats (dried, cured and fermented), while only one out of four samples of raw meat contained benzene $\left(1.25 \mu \mathrm{g} \mathrm{kg}^{-1}\right)$.

In the food category of cereal products, 18 samples of breakfast cereals were analyzed and all samples contained benzene with contamination levels ranging from 1.23 to $7.15 \mu \mathrm{g} \mathrm{kg}^{-1}$. Possible causes for the high incidence of benzene in these products could be due to the production process (thermal treatment-extrusion), addition of aromas or packaging. Additional breakfast cereal (extruded) samples were taken from an industrial production line, before packaging and analyzed for benzene contents. Of four analyzed samples, one sample contained benzene $\left(0.83 \mu \mathrm{g} \mathrm{kg}^{-1}\right)$. Although the number of samples taken from the production line is very limited and representative of only one production site, these results could be an indication that benzene contamination could occur after packaging. To identify the exact origin of benzene contamination during food processing an in-depth analysis of each processing is required. The importance of several other contamination routes such as packaging, origin of the food, ingredients, or cross contamination from the environment, requires further investigation as demonstrated by the examples shown in this study.

In addition to the food samples presented in Table 2, benzene was also determined in aromas which are used in food processing such as, vanilla, nuts, chocolate, pistachio, orange flower, cola and mint. Benzene was found >LOD in five out of seven analyzed samples with concentrations ranging from $11.41 \mu \mathrm{g} \mathrm{kg}^{-1}$ to 449 $4.77 \mu \mathrm{g} \mathrm{kg}^{-1}$ in the positive samples. These aromas included both natural and synthetic products and no link could be established between benzene occurrence and product origin. Since aroma production is based on a concentration process, this could be the explanation for the high levels of benzene in these samples. Benzene results of aromas analysis were not included in Table 2 and neither considered for the exposure assessment since intake data for aromas are unavailable. Nevertheless, the presence of aromas in certain foods could be an important source of benzene concentrations in food.

The discovery of benzene formation from benzoate prompted special attention towards non-alcoholic drinks, in particular beverages (Fabietti et al., 2001; Cao et al., 2007; Van Poucke et al., 2008; Lachenmeier et al., 2008; Cao and Casey, 2008; Nyman et al., 2008; Haws et al., 2008; Nyman et al., 2010), since these often contain 
added benzoate as a preservative. Consequently, several manufactures have reevaluated their formulation in order to minimize benzene formation (Mcneal et al., 1993; ICBA, 2006; Nyman et al., 2008). In the present study, 52 samples of non-alcoholic drinks were analyzed of which 22 samples (all different products) contained added benzoate (according to product label). Benzene was detected in $\sim 60 \%$ of the benzoate containing samples with the highest values occurring in concentrate juices (up to $11.52 \mu \mathrm{g} \mathrm{kg}^{-1}$ ). A possible explanation could be due to high temperatures used during the production process and/or the concentration process itself. However, results here reported regard to diluted product according to label instructions. Van Poucke et al. (2008) monitored benzene contents in 134 soft drinks of the Belgian market. Based on statistical analysis, these authors reported that besides benzoic acid, ascorbic acid, acidity regulators and packaging may also influence greatly benzene formation in beverages.

\subsection{Exposure assessment}

Foodstuffs considered in the sampling plan of this study represent approximately $91 \%$ of consumed foods reported in the BNFCS database. The remaining $9 \%$ include vegetables - $6 \%$ (onions, sweet potatoes, cabbages and mushrooms), meat - 0.6\% (duck, rabbit, goat, horse, offals, etc.), sauces - $0.5 \%$ (ketchup and ice-cream toppings), alcoholic drinks $-1.4 \%$ (cocktails, fortified wines and liquors) and miscellaneous - $0.6 \%$ (artificial sweeteners, animal fats, dietetics, spices, etc.). The sampling plan applied in this study was broad enough to cover the most consumed foodstuffs by the Belgian population. Furthermore, since the minimum number of samples (386) required for the exposure assessment of a contaminant in food (considering a $50 \%$ of prevalence, with a $95 \%$ confidence level) (EFSA, 2006) was attained, it might be concluded that the study was statistically valid.

\subsubsection{Probabilistic analysis}

In probabilistic analysis every possible value that each variable can have and the weight of each possible scenario for the probability of its occurrence is taken in consideration (Vose, 1996), therefore allowing a more accurate benzene intake estimation. In this regard, both food consumption and benzene content data were fitted to best fit distributions according to the @Risk software for the inserted data (Table 3). During the distribution fitting, the observed cumulative distributions were plotted against the theoretical cumulative distributions. The probability-probability (P-P) plots provided roughly a straight line joining the diagonals if the observed cumulative distribution could well be defined by the theoretical cumulative distributions. The more the data were available, the more theoretical cumulative distribution approximated the observed cumulative distribution. The distribution fitting was possible when there were at least five data values, among which three data values had to be positive. During fitting of the distributions to benzene data, deviations from normal distribution line were observed. This deviation may be explained by presence of the data below the LOD which counted $42 \%$. In case where fitting distribution was not possible, due to insufficient numbers of observed data for benzene, the mean value was used instead. This was applied for example in the categories of alcoholic drinks and fruits and vegetables which contained only one and two positive contamination data, respectively (Table 2 ).

Table 4 presents probabilistic estimates of benzene intake ( $\mu \mathrm{g} \mathrm{kg} \mathrm{bw} \mathrm{d}^{-1}$ ) for the upper bound (worst case scenario), while there was no significant difference $(p<0.05)$ between the lower, medium and upper bounds. This can be explained by the low LOD from the analytical method used and due to the percentage of non-detects not being very high. Total estimated benzene mean and $\mathrm{P} 99.5$ intakes were 0.020 and $0.122 \mu \mathrm{g} \mathrm{kg} \mathrm{bw} \mathrm{d}^{-1}$, respectively. These values are below the MRL for chronic oral exposure $\left(0.5 \mu \mathrm{g} \mathrm{kg} \mathrm{bw} \mathrm{d}^{-1}\right)$ (ATSDR, 2007) and accordingly could indicate

Table 3

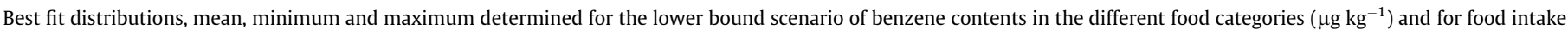
$\left(\mu \mathrm{gg} \mathrm{bw} \mathrm{d}{ }^{-1}\right)$.

\begin{tabular}{|c|c|c|c|c|c|}
\hline Food category & Variable & Function & Min & Mean & Max \\
\hline \multirow[t]{2}{*}{ Non-alcoholic drinks } & Benzene contents & RiskExpon(0.81634, RiskShift(-0.017007)) & -0.0170 & 0.7993 & $+\infty$ \\
\hline & Food intake & RiskNormal $(0.0069848,0.0035333)$ & $-\infty$ & 0.0070 & $+\infty$ \\
\hline \multirow[t]{2}{*}{ Alcoholic drinks } & Benzene contents & Mean & 0.0000 & 0.1004 & 1.0045 \\
\hline & Food intake & RiskLoglogistic(0.00091845, 0.0036393,4.8913) & 0.0009 & 0.0058 & $+\infty$ \\
\hline \multirow[t]{2}{*}{ Sauces } & Benzene contents & RiskInvgauss $(1.3549,0.8095$, RiskShift $(-0.17447))$ & -0.1745 & 1.1804 & $+\infty$ \\
\hline & Food intake & RiskExpon(0.00020566, RiskShift(0.0000703862)) & 0.0000 & 0.0003 & $+\infty$ \\
\hline \multirow[t]{2}{*}{ Dairy products } & Benzene contents & RiskUniform $(-0.035259,1.3046)$ & -0.0353 & 0.6347 & 1.3046 \\
\hline & Food intake & RiskInvgauss(0.001316,0.00096503, RiskShift(0.00032899)) & 0.0003 & 0.0016 & $+\infty$ \\
\hline \multirow[t]{2}{*}{ Fruits and vegetables } & Benzene contents & Mean & 0.0000 & 0.1120 & 2.1300 \\
\hline & Food intake & RiskPearson5(10.133, 0.025911, RiskShift(-0.00019129)) & -0.0002 & 0.0026 & $+\infty$ \\
\hline \multirow[t]{2}{*}{ Meat and meat products } & Benzene contents & RiskExpon(1.4743, RiskShift $(-0.054604))$ & -0.0546 & 1.4197 & $+\infty$ \\
\hline & Food intake & RiskExpon(0.00037917, RiskShift(0.0004448)) & 0.0004 & 0.0008 & $+\infty$ \\
\hline \multirow[t]{2}{*}{ Fish and fish products } & Benzene contents & RiskExpon(6.8651, RiskShift( $(-0.15602))$ & -0.1560 & 6.7091 & $+\infty$ \\
\hline & Food intake & RiskBetaGeneral $(1.4454,44.002,0.00060722,0.018951)$ & 0.0006 & 0.0012 & 0.0189 \\
\hline \multirow[t]{2}{*}{ Cereal products } & Benzene contents & RiskExtvalue $(1.4215,1.4556)$ & $-\infty$ & 2.2617 & $+\infty$ \\
\hline & Food intake & RiskPearson5(3.7563, 0.0021528, RiskShift(0.0000696818)) & 0.0000 & 0.0009 & $+\infty$ \\
\hline \multirow[t]{2}{*}{ Cookies and cakes } & Benzene contents & RiskBetaGeneral $(0.26115,0.25162,0,1.5079)$ & 0.0000 & 0.7680 & 1.5079 \\
\hline & Food intake & RiskInvgauss(0.00021627, 0.00014071, RiskShift(0.0000805236)) & 0.0000 & 0.0003 & $+\infty$ \\
\hline \multirow[t]{2}{*}{ Fats and oils } & Benzene contents & RiskInvgauss $(1.7585,2.8653$, RiskShift $(-0.29231))$ & -0.2923 & 1.4662 & $+\infty$ \\
\hline & Food intake & RiskLogistic(0.00030569, 0.00010737) & $-\infty$ & 0.0003 & $+\infty$ \\
\hline \multirow[t]{2}{*}{ Ready to eat meals } & Benzene contents & RiskInvgauss $(2.2661,0.67844$, RiskShift $(-0.15196))$ & -0.1520 & 2.1141 & $+\infty$ \\
\hline & Food intake & RiskInvgauss $(0.00081029,0.00232312, \operatorname{RiskShift}(0.00023408))$ & 0.0002 & 0.0010 & $+\infty$ \\
\hline \multirow[t]{2}{*}{ Sugar and confectionery } & Benzene contents & RiskTriang $(0,0,2.9512)$ & 0.0000 & 0.9837 & 2.9512 \\
\hline & Food intake & RiskPearson5(3.7028, 0.0016004, RiskShift(0.00012675)) & 0.0001 & 0.0007 & $+\infty$ \\
\hline \multirow[t]{2}{*}{ Miscellaneous } & Benzene contents & RiskBetaGeneral $(0.18388,0.30903,0,2.5168)$ & 0.0000 & 0.9389 & 2.5168 \\
\hline & Food intake & RiskLoglogistic(0.00046336, 0.0010197, 3.574) & 0.0005 & 0.0016 & $+\infty$ \\
\hline \multirow[t]{2}{*}{ Fresh eggs } & Benzene contents & Mean & 0.0000 & 0.0000 & 0.0000 \\
\hline & Food intake & RiskLoglogistic(0.00035327, 0.00044938, 5.9534) & 0.0004 & 0.0008 & $+\infty$ \\
\hline \multirow[t]{2}{*}{ All foods combined } & Benzene contents & $\operatorname{RiskExpon}(1.7418, \operatorname{RiskShift}(-0.0039768))$ & -0.0040 & 1.7378 & $+\infty$ \\
\hline & Food intake & RiskLognorm(0.014471, 0.0044011, RiskShift(-0.0041324)) & -0.0041 & 0.0103 & $+\infty$ \\
\hline
\end{tabular}


Table 4

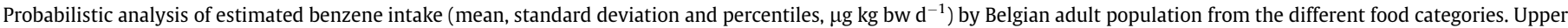
bound corresponds to benzene $(<\mathrm{LOD})$ treated as LOD.

\begin{tabular}{|c|c|c|c|c|c|c|c|}
\hline \multirow[t]{2}{*}{ Food category } & \multicolumn{7}{|c|}{ 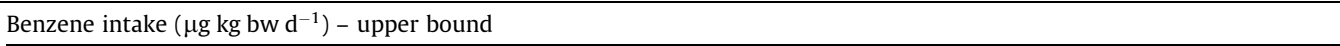 } \\
\hline & Mean & Std & P 50 & P 75 & P 90 & P 97.5 & Р 99.5 \\
\hline Non-alcoholic drinks & 0.006 & 0.007 & 0.004 & 0.008 & 0.014 & 0.025 & 0.039 \\
\hline Alcoholic drinks & 0.001 & 0.000 & 0.001 & 0.001 & 0.001 & 0.002 & 0.003 \\
\hline Sauces & 0.000 & 0.001 & 0.000 & 0.000 & 0.001 & 0.002 & 0.004 \\
\hline Dairy products & 0.001 & 0.001 & 0.001 & 0.001 & 0.003 & 0.005 & 0.008 \\
\hline Fruits and vegetables & 0.003 & 0.002 & 0.003 & 0.004 & 0.006 & 0.008 & 0.010 \\
\hline Meat and meat products & 0.001 & 0.001 & 0.001 & 0.002 & 0.003 & 0.005 & 0.009 \\
\hline Fish and fish products & 0.008 & 0.009 & 0.005 & 0.011 & 0.018 & 0.032 & 0.052 \\
\hline Cereal products & 0.002 & 0.002 & 0.001 & 0.003 & 0.004 & 0.007 & 0.002 \\
\hline Cookies and cakes & 0.000 & 0.000 & 0.000 & 0.000 & 0.001 & 0.001 & 0.002 \\
\hline Fats and oils & 0.001 & 0.021 & 0.000 & 0.001 & 0.001 & 0.004 & 0.016 \\
\hline Ready to eat meals & 0.002 & 0.002 & 0.002 & 0.003 & 0.005 & 0.009 & 0.014 \\
\hline Sugar and confectionery & 0.001 & 0.001 & 0.001 & 0.001 & 0.002 & 0.003 & 0.004 \\
\hline Miscellaneous & 0.002 & 0.002 & 0.002 & 0.003 & 0.004 & 0.006 & 0.009 \\
\hline Fresh eggs & 0.000 & 0.000 & 0.000 & 0.000 & 0.001 & 0.001 & 0.001 \\
\hline Total intake & 0.020 & 0.021 & 0.013 & 0.025 & 0.045 & 0.078 & 0.122 \\
\hline
\end{tabular}

that benzene concentrations found in analyzed foods pose a low risk to the Belgian population.

\subsubsection{Uncertainty evaluation of the exposure assessment}

Inherently associated to exposure assessments are uncertainties that need to be considered for the interpretation of the results here presented. Factors intrinsic to food consumption surveys such as under/over reporting of consumption data, misreporting of consumed foods in wrong food groups and the erroneous estimation of consumed quantities (based on figures or portion sizes) could contributed to an under/overestimation of food consumption and affect the exposure assessment. Moreover, consumption data used in this study were surveyed in 2004 and surely eating habits may have changed over time, and probably towards higher consumption of ready to eat meals and spreadable salads. This could contribute for an underestimation of benzene intake in the present study.

Several organizations have performed benzene dietary estimations, and these are summarized in Becalski and Nyman (2009). Overall the exposure assessments vary between the different studies (ranging from 0.003 to $5 \mu \mathrm{g} \mathrm{kg} \mathrm{bw} \mathrm{d}^{-1}$ ). Such discrepancies could be explained due to different methodologies used to estimate dietary intakes, differences in food consumptions surveys data and benzene quantification.

\section{Conclusions}

It has been reported that inhalation of contaminated air was the major route of non-occupational benzene exposure for nonsmokers $\left(3.3 \mu \mathrm{g} \mathrm{kg} \mathrm{bw} \mathrm{d}^{-1}\right)$, while mainstream cigarette smoke was the primary route for smokers $\left(33.3 \mu \mathrm{g} \mathrm{kg} \mathrm{bw} \mathrm{d}^{-1}\right.$ ) (Becalski and Nyman, 2009). Recently Ragas et al. (2011) published a cumulative risk assessment of exposure in urban environments for benzene, among other chemicals. Based on their assumptions $48 \%$ of the adult urban population might be exposed to benzene by inhalation at a concentration above the EU limit $\left(5 \mu \mathrm{g} \mathrm{m}^{-3}\right)$. The calculated hazard index (HI) for benzene is higher than 1 and $\mathrm{HI}$ values $>1$ indicate that the acceptable level for urban citizens has been exceeded. Knowing that Belgium is the third most densely populated country of the EU (Eurostat, 2011), it can be assumed that there is little or no margin for additional exposure to benzene via food in Belgium. On the other hand, the quantitative estimation of dietary exposure to benzene performed in the present study showed that benzene exposure via food is minor in comparison with exposure via inhalation. Nonetheless, considering that ingested benzene is approximately $100 \%$ absorbed by the human body versus $50 \%$ by inhalation benzene and that benzene being a genotoxic carcinogen (one single molecule may trigger cancer formation), food categories with higher risk of benzene occurrence should be monitored and the main sources of benzene in these foods at most risk further investigated. As seen in the results, the highest benzene concentrations occurring in food were found in processed foodstuffs of animal origin, such as smoked fish and meat, or sterilized in closed recipients. High levels of benzene present in aromas could indicate that these could be an additional source of benzene in certain foods. So far, attention on benzene in foods has mainly focused on the addition of benzoic and ascorbic acids in foodstuffs. Thus, other processing conditions possibly leading to benzene occurrence in food should be reviewed, e.g. benzene limits in smoking processes and aromas, source of benzene in breakfast cereals, etc.

With respect to the MOE values for oral intake of benzene, the application of the mean and P 99.5 dietary benzene estimations determined in this study and considering a $\mathrm{BMDL}_{10}$ of 17.6 $\mathrm{mg} \mathrm{kg} \mathrm{bw} \mathrm{d}^{-1}$ derived from female rat Zymbal gland carcinoma (Benford et al., 2010), the re-calculated MOE values would range from 144262 to 880000 . Although the magnitude of these MOE values are reduced to at least half compared to the ones initially reported by Smith et al. (2010) and Benford et al. (2010), these still remain considerably higher than 10000 , and therefore considered to be of low concern from a public health point of view when compared to other chemical hazards in food (EFSA, 2005).

\section{Acknowledgments}

Financial support by the Federal Public Service of Health, Food Chain Safety and Environment (Contract 08/02 Benzene) is gratefully acknowledged. The authors would like to acknowledge the Belgian Scientific Institute of Public Health for access to the consumption data. The authors also thank Dr. Eric Deconinck, Christine Hoefkens and Stefanie Vandevijvere for the fruitful discussions and Carine Hoorelbeke for support with sample preparation.

\section{References}

Ahn, D.U., 2002. Production of volatiles from amino acid homopolymers by irradiation. J. Food Sci. 67, 2565-2570.

ATSDR, 2007. ToxGuide ${ }^{\mathrm{TM}}$ for Benzene $\mathrm{C}_{6} \mathrm{H}_{6}$, CAS \#71-43-2. <http:/ www.atsdr.cdc.gov/toxguides>.

Becalski, A., Nyman, P., 2009. Benzene. in: Stadler, R.H., Lineback, D.R. (Eds.) Process-Induced Food Contaminants - Occurrance, Formation, Mitigation, and Health Risks. Wiley, pp. 413-444.

Benford, D., Bolger, P.M., Carthew, P., Coulet, M., DiNovi, M., Leblanc, J.C., Renwick, A.G., Setzer, W., Schlatter, J., Smith, B., Slob, W., Williams, G., Wildemann, T. 
2010. Application of the margin of exposure (MOE) approach to substances in food that are genotoxic and carcinogenic. Food Chem. Toxicol. 48, S2-S24.

Bolzoni, L., Barbieri, G., Virgili, R., 1996. Change in volatile compounds of Parma ham during maturation. Meat Sci. 43, 301-310.

Cao, X.L., Casey, V., 2008. Improved method for the determination of benzene in soft drinks at sub-ppb levels. Food Addit. Contam. 25, 401-405.

Cao, X.L., Casey, V., Seaman, S., Tague, B., Becalski, A., 2007. Determination of benzene in soft drinks and other beverages by isotope dilution headspace gas chromatography/mass spectrometry. J. of AOAC Int. 90, 479-484.

De Vriese, S., De Backer, G., De Henauw, S., Huybrechts, I., Kornitzer, K., Leveque, A., Moreau, M., Van Oyen, H., 2005. The Belgian food consumption survey: aims, design and methods. Arch. Pub. Health 63, 1-16.

EC, 1995. European Parliment and Council Directive 95/2/EC of 20 February 1995 on food additives other than colours and sweeteners.

EC, 1998. Council Directive 98/83/EC on the quality of water intended for human consumption. <http://eur-lex.europa.eu.L330>.

EFSA, 2005. European Food Safety Authority. Opinion of the Scientific Committee on a request from EFSA related to a harmonised approach for risk assessment of substances which are both genotoxic and carcinogenic. EFSA J. 1-30.

EFSA, 2006. European Food Safety Authority. Report on proposed technical specifications for a coordinated monitoring programme for Salmonella and Campylobacter in broiler meat in the EU. 92.

Eurostat, 2011. Eurostat data. <http://epp.eurostat.ec.europa.eu/tgm/ table.do? tab=table\&init=1\&language $=e n \&$ pcode $=$ tps $00003 \&$ plugin $=1>$.

Fabietti, F., Delise, M., Bocca, A.P., 2001. Investigation into the benzene and toluene content of soft drinks. Food Control 12, 505-509.

Fleming-Jones, M.E., Smith, R.E., 2003. Volatile organic compounds in foods: a five year study. J. Agric. Food Chem. 51, 8120-8127.

Gardner, L.K., Lawrence, G.D., 1993. Benzene production from decarboxylation of benzoic-acid in the presence of ascorbic-acid and a transition-metal catalyst. J. Agric. Food Chem. 41, 693-695.

German Institute of Human Nutrition Postdam-Rehbrücke (DIfE), 2010. The Multiple Source Method (MSM). <https://nugo.dife.de/msm/>.

Haws, L.C., Tachovsky, J.A., Williams, E.S., Scott, L.L.E., Paustenbach, D.J., Harris, M.A. 2008. Assessment of potential human health risks posed by benzene in beverages. J. Food Sci. 73, T33-T41.

Heikes, D.L., Jensen, S.R., Fleming-Jones, M.E., 1995. Purge-and-trap extraction with GC-MS determination of volatile organic-compounds in table-ready foods. J. Agric. Food Chem. 43, 2869-2875.

IARC, 1987. Benzene - IARC Monographs on the Evaluation of Carcinogenic Risks to Humans, 1-42 ed. International Agency for Research on Cancer, France, Lyon (Suppl. 7).

ICBA, 2006. Guidance Document to Mitigate the Potential for Benzene Formation in Beverages; International Council of Beverages Association; Washington, D.C. 06.

Jickells, S.M., Crews, C., Castle, L., Gilbert, J., 1990. Headspace analysis of benzene in food contact materials and its migration into foods from plastics cookware. Food Addit. Contam. 7, 197-205.

Kjallstrand, J., Petersson, G., 2001. Phenolic antioxidants in alder smoke during industrial meat curing. Food Chem. 74, 85-89.

Knox, R.C., Canter, L.W., 1996. Prioritization of ground water contaminants and sources. Water Air Soil Poll. 88, 205-226.

Lachenmeier, D.W., Reusch, H., Sproll, C., Schoeberl, K., Kuballa, T., 2008. Occurrence of benzene as a heat-induced contaminant of carrot juice for babies in a general survey of beverages. Food Addit. Contam. A 25, 1216-1224.

Long, D.G., 1999. From cobalt to chloropropanol: de tribulationibus aptis cerevisiis imbibendis. J. Inst. Brewer. 105, 79-84.

Masohan, A., Parsad, G., Khanna, M.K., Chopra, S.K., Rawat, B.S., Garg, M.O., 2000. Estimation of trace amounts of benzene in solvent-extracted vegetable oils and oil seed cakes. Analyst 125, 1687-1689.
Matthews, R.W., Sangster, D.F., 1965. Measurement by benzoate radiolytic decarboxylation of relative rate constants for hydroxyl radical reactions. J. Phys. Chem. 69, 1938-1946.

Mcneal, T.P., Nyman, P.J., Diachenko, G.W., Hollifield, H.C., 1993. Survey of benzene in foods by using headspace concentration techniques and capillary gaschromatography. J. AOAC Int. 76, 1213-1219.

Medeiros Vinci, R., Canfyn, M., De Meulenaer, B., de Schaetzen, T., Van Overmeire, I., De Beer, J., Van Loco, J., 2010. Determination of benzene in different food matrices by distillation and isotope dilution HS-GC/MS. Anal. Chim. Acta 672, 124-129.

Medeiros Vinci, R., De Meulenaer, B., Andjelkovic, M., Canfyn, M., Van Overmeire, I., Van Loco, J., 2011. Factors influencing benzene formation from the decarboxylation of benzoate in liquid model systems. J. Agric. Food Chem. http://dx.doi.org/10.1021/jf203233s

Nyman, P.J., Diachenko, G.W., Perfetti, G.A., Mcneal, T.P., Hiatt, M.H., Morehouse, K.M., 2008. Survey results of benzene in soft drinks and other beverages by headspace gas chromatography/mass spectrometry. J. Agric. Food Chem. 56, 571-576.

Nyman, P.J., Wamer, W.G., Begley, T.H., Diachenko, G.W., Perfetti, G.A., 2010. Evaluation of accelerated UV and thermal testing for benzene formation in beverages containing benzoate and ascorbic acid. J. Food Sci. 75, C263-C267.

Ragas, A.M.J., Oldenkamp, R., Preeker, N.L., Wernicke, J., Schlink, U., 2011. Cumulative risk assessment of chemical exposures in urban environments. Environ. Int. 37, 872-881.

Smith, B., Cadby, P., DiNovi, M., Setzer, R.W., 2010. Application of the margin of exposure (MoE) approach to substances in food that are genotoxic and carcinogenic example: benzene, CAS: 71-43-2. Food Chem. Toxicol. 48, S49S56.

Sommers, C., Delincée, H., Smith, J., Marchioni, E., 2006. Toxicological safety of irradiated foods. in: Sommers, C. Fan, X. (Eds.). Food Irradiation - Research and Technology, Blackwell Publishing, pp. 43-61.

US EPA, 1985. Final draft for drinking water criteria document on benzene. Health Effcets Branch: Criteria and Standards Division.

Van Poucke, C., Detavernier, C., Van Bocxlaer, J.F., Vermeylen, R., Van Peteghem, C., 2008. Monitoring the benzene contents in soft drinks using headspace gas chromatography-mass spectrometry: a survey of the situation on the Belgian market. J. Agric. Food Chem. 56, 4504-4510.

Vandevijvere, S., Andjelkovic, M., De Wil, M., Vinkx, C., Huybrechts, I., Van Loco, J., Van Oyen, H., Goeyens, L., 2009. Estimate of intake of benzoic acid in the Belgian adult population. Food Addit. Contam. A 26, 958-968.

Varner, S.L., Hollifield, H.C., Andrzejewski, D., 1991. Determination of benzene in polypropylene food-packaging materials and food-contact paraffin waxes. J. Assoc. Anal. Chem. 74, 367-374.

Vose, D., 1996. Quantitative Risk Analysis: A Guide to Monte Carlo Simulation modelling. West Sussex, J. Wiley and Sons LTD.

WHO, 1996. Benzene in drinking-water, Background document for the development of WHO guidelines for drinking water quality, World Health Organization, Geneva.

Wittkowski, R., Baltes, W., Jennings, W.G., 1990. Analysis of liquid smoke and smoked meat volatiles by headspace gas-chromatography. Food Chem. 37, 135144.

Wu, Q.J., Lin, H., Fan, W., Dong, J.J., Chen, H.L., 2006. Investigation into benzene, trihalomethanes and formaldehyde in Chinese lager beers. J. Inst. Brewer. 112, 291-294.

Zhu, M.J., Mendonca, A., Min, B., Lee, E.J., Nam, K.C., Park, K., Du, M., Ismail, H.A., Ahn, D.U., 2004. Effects of electron beam irradiation and antimicrobials on the volatiles, color, and texture of ready-to-eat turkey breast roll. J. Food Sci. 69, C382-C387. 